\title{
La asesoría de tesis en pregrado: una labor que requiere un nuevo enfoque
}

\author{
Undergraduate thesis advising: a task that requires a new approach
}

\section{Sr. Editor:}

Ante la problemática de la producción científica estudiantil en el Perú (1), y aún más la producción científica de los docentes que asesoran tesis (2), tema discutido en el artículo de Corrales-Reyes, ReyesPerez y Diaz-Santoya (3), es necesario hacer una reflexión admitiendo que existe un vínculo entre la responsabilidad del asesor de tesis con la producción científica estudiantil. En ese sentido, se espera que el docente que supervisa trabajos de grado oriente la generación de nuevo conocimiento, sin embargo, la literatura científica revela que en su mayoría los asesores no incentivan a publicar las tesis (4), pues los resultados de algunas investigaciones concluyen que la tasa de publicación de estos trabajos es baja y preocupante (5); por lo tanto, la labor de quienes ejercen asesoría está muy alejada del compromiso para impulsar la investigación científica (6) en un país que tenía la proyección más baja de producción de nuevo conocimiento en Sudamérica para el 2015 (7).

Por lo anterior, es necesario enfatizar que la labor de un asesor de tesis debe ir más allá de la orientación temática y metodológica, además, quienes tenemos experiencia en este campo, reconocemos que para generar investigaciones con impacto social y potencial publicable no son suficientes reuniones para evaluar qué hizo o debe hacer el tesista, más bien, en un esfuerzo por comprender su realidad uno se da cuenta que este no solo enfrenta la elaboración del trabajo, sino también, factores de corte institucional como trámites engorrosos, personales como temor hacia la investigación o estadística, falta de recursos económicos, deserción estudiantil, estrés académico, y todo esto, muchas veces ignorado por el asesor, quien lo único que ven en él es un recurso que agotar y no un talento a gestionar.

Frente a este escenario, queda claro que es un error orientar el esfuerzo de un tesista hacia el día de la sustentación, y por ello, es necesario complementar el asesoramiento con nuevas estrategias como el coaching académico, cuyo principal actor viene a ser el coach, término que proviene del argot universitario ingles del siglo XVIII, aludiendo a un profesor particular que ayudaba a un estudiante a prepararse con eficiencia para un examen, y aún en la actualidad, este sentido prevalece porque se entiende que la aplicación del coaching implica transportar a las personas desde donde se encuentran hoy hasta donde les gustaría estar mañana, siendo el coach el facilitador de este viaje (8). Esta posición en la investigación formativa, se comprende como un proceso sistemático de aprendizaje, donde el tesista tiene la posibilidad de desarrollar competencias investigativas, tomando el asesor, la posición de un coach que planifica de manera conjunta las metas a lograr con la investigación, que motiva al tesista durante el proceso que implica su realización, que demuestra con el ejemplo cómo generar nuevo conocimiento, y además, que ofrezca un feedback constructivo que revele los avances y aprendizajes logrados (9).

Por lo tanto, la aparición de la figura del asesorcoach, quien se caracteriza por saber escuchar y atender, ser competente, mantener buen ánimo, tener una metodología clara y precisa, y sobre todo mostrar compromiso con la formación de investigadores para el país, es necesaria en tiempos donde la tesis tiene un sentido más de requisito para laborar, que de aporte al conocimiento científico.

\section{Oscar J. Mamani-Benito 1,2,3,a}

\section{Correspondencia:}

Oscar Javier Mamani-Benito

Avenida Simón Bolivar \#1019, Puno

Teléfono: 51959925651.

ORCID: https://orcid.org/0000-0002-9818-2601

Correo electrónico: oscar.mb@upeu.edu.pe 


\section{REFERENCIAS BIBLIOGRÁFICAS}

1. Huaraca CM, Apaza A, Mejia C. Realidad peruana de la publicación científica estudiantil en los últimos diez años. Educación Médica Superior. 2017; 31(3):00. (Citado el 20 de febrero de 2019) Disponible en: http://www.ems.sld.cu/index.php/ems/article/ view/1019/624

2. Alarcon-Ruiz CA, Quezada MA. Publicación de artículos científicos por asesores de tesis de una Facultad de Medicina. Revista Médica Herediana. 2018; 29(3):152-157. DOI: https://doi.org/10.20453/ rmh.v29i3.3403

3. Corrales-Reyes IE, Reyes- Pérez JJA, Díaz-Santoya MLA. Asesores de tesis y publicación de artículos científicos en el pregrado. Revista Médica Herediana. 2018; 29(4):264-265. DOI: https://doi.org/10.20453/ rmh.v29i4.3454

4. Mejia R, Cáceres J, Vera A, Inga-Berrospi F, MaytaTristán P. Percepción y factores asociados a insatisfacción que los médicos recién graduados tienen de sus asesores de tesis, Lima-Perú. Educación Médica. 2016;30(4):340-348. (Citado el 20 de febrero de 2019) Disponible en: http://scielo.sld. cu/scielo.php?script=sci_arttext\&pid $=$ S0864-21412016000400010

5. Sánchez-Duque JA, Gómez-González JF, Rodríguez-Morales AJ. Publicación desde el pregrado en Latinoamérica: dificultades y factores asociados en estudiantes de Medicina. Investig en Educación Medica. 2017; 6(22):104-8. (Citado el 20 de febrero de 2019) Disponible en: http://www. redalyc.org/pdf/3497/349750523007.pdf
6. Morillo M. Labor del tutor y asesor de trabajo de investigación: Experiencias e incentivos. EDUCERE. 2009; 19(47): 919-30. (Citado el 20 de febrero de 2019) Disponible en: http://www.saber.ula.ve/ bitstream/handle/123456789/31485/articulo3.pdf;jse ssionid=AD729D5F01682D8EC0E47042DF78AF11 ?sequence $=1$

7. Alarco J, Changllio-Calle G, Cahuana-Salazar M. Investigación en pregrado: interés según sexo y ciclo académico. Educación Médica. 2017; 18(1):6773. (Citado el 20 de febrero de 2019) Disponible en: http://linkinghub.elsevier.com/retrieve/pii/ S1575181316300444

8. Sánchez B, Boronat J. Coaching educativo: Modelo para el desarrollo de competencias intra e interpersonales. Educación XX1. 2013;17(1):22141. https://doi.org/10.5944/educxx1.17.1.10712

9. Sánchez-Teruel D. El coaching pedagógico dentro del sistema educativo: innovando procesos. Revista Intercontinental de Psicología y Educación. 2013; 15(2):171-91. (Citado el 20 de febrero de 2019) Disponible en: http://www.redalyc.org/ pdf/802/80228344010.pdf

Recibido: 01/03/2019

Profesor en la Escuela de Posgrado de la Universidad Peruana Unión. Lima, Perú.

2 Docente investigador en Universidad Peruana Unión. Juliaca, Perú

3 Docente investigador en Universidad Privada San Carlos. Puno, Perú.

a Magister en Educación 